\title{
MicroRNA regulation of cancer stem cells in the pathogenesis of breast cancer
}

\author{
Tong Niu ${ }^{1,2}$, Weiwei Zhang ${ }^{1}$ and Wei Xiao ${ }^{1,2^{*}}$ (1)
}

\begin{abstract}
Breast cancer is the most common cancer among women and accounts for $30 \%$ of all female malignancies worldwide. Breast cancer stem cells (BCSCs) are a small population of breast cancer cells that exhibit multiple characteristics including differentiation capacity, self-renewal and therapeutic resistance. Recently, BCSCs have attracted attention due to their modulation of breast tumor behaviors and drug resistance. miRNAs are small noncoding mRNAs involved in virtually all biological processes, including stem cell development, maintenance and differentiation. In breast cancer, miRNAs appear to be multi-faceted since they can act as either suppressors or oncogenes to regulate breast cancer progression. This review summarizes the critical roles of miRNAs in regulating multiple signaling pathways such as Wnt/B-catenin, Notch, PI3K/AKT/mTOR, BMI-1 and STAT3 that are important for the BCSC maintenance.
\end{abstract}

Keywords: Breast cancer, Breast cancer stem cell (BCSC), miRNA, Self-renewal, Therapeutic resistance

\section{Background}

Breast cancer $(\mathrm{BC})$ is the most common female cancer in terms of high incidence and mortality rate all over the world. The prevalence of $\mathrm{BC}$ is increasing to estimated 42,690 deaths and 279,100 new cases in the United States in 2020 (https://doi.org/10.3322/caac.21590). In women, $\mathrm{BC}$ is the most common type of cancer $(25 \%)$ and the leading cause of cancer deaths (15\%) [1]. High hormonal status, such as estrogen, estrogen receptor (ER), progesterone receptor (PR) and human epidermal growth factor receptor (HER2), are the most important factors promoting $\mathrm{BC}$ onset and progression. Four distinct breast cancer subtypes have been classified based on the expression of the proliferation marker (Ki67) and the hormonal status including Luminal A, Luminal B (HER2 negative), Luminal B (HER2 positive), HER2 (non-luminal) and triplenegative breast cancer (TNBC) [2] (Table 1).

Many clinical and pathological factors determine the prognosis of BC. In the past decades, a number of cellular

\footnotetext{
*Correspondence: wei.xiao@usask.ca

${ }^{2}$ Department of Biochemistry, Microbiology and Immunology, University of Saskatchewan, Saskatoon, SK S7N 5E5, Canada
}

Full list of author information is available at the end of the article factors such as onco-proteins, circulating tumor cells, mutations in some specific genes, microRNAs (miRNAs) and cancer stem cells (CSCs) were proposed to be potential parameters for the prognosis of breast cancers [3]. CSCs in BC tissues lead to uncertainty for breast cancer treatment. CSCs were first detected in human acute myeloid leukemia (AML) and they are highly malignant, as they facilitate tumor metastasis, relapse, tumor progression and confer resistance to cancer therapy. Besides the common cancer cell capability such as migration and invasion, these cells exhibit characteristic stem cell properties including differentiation, self-renewal and tumorinitiation [4]. Increasing evidence shows that CSCs are closely associated with the pathogenesis and progression of various cancers, such as pancreatic, colon, prostate, brain and breast cancers. They could confer resistance to therapeutic agents and contribute to the propagation of neoplastic cells for tumor heterogeneity [5]. Somatic and normal stem cells could serve as sources of CSCs under abnormal genetic and epigenetic changes.

miRNAs are small non-coding RNAs with a length of 21-25 nucleotides which are known to regulate more than $60 \%$ of human genes at the post-transcriptional level by targeting 3'-untranslated regions (3'-UTR) of mRNAs

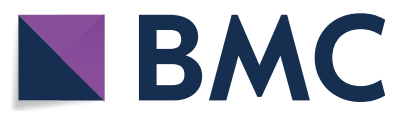

c) The Author(s) 2021. This article is licensed under a Creative Commons Attribution 4.0 International License, which permits use, sharing, adaptation, distribution and reproduction in any medium or format, as long as you give appropriate credit to the original author(s) and the source, provide a link to the Creative Commons licence, and indicate if changes were made. The images or other third party material in this article are included in the article's Creative Commons licence, unless indicated otherwise in a credit line to the material. If material is not included in the article's Creative Commons licence and your intended use is not permitted by statutory regulation or exceeds the permitted use, you will need to obtain permission directly from the copyright holder. To view a copy of this licence, visit http://creativeco mmons.org/licenses/by/4.0/. The Creative Commons Public Domain Dedication waiver (http://creativecommons.org/publicdomain/ zero/1.0/) applies to the data made available in this article, unless otherwise stated in a credit line to the data. 
Table 1 The subtypes of breast cancer classified via expression of Ki67 and hormonal status

\begin{tabular}{|c|c|}
\hline Subtypes & The expression of Ki67 and hormonal status \\
\hline \multirow[t]{4}{*}{ Luminal A } & Estrogen positive $(E R+)$ \\
\hline & Progesterone receptor $(P R) \geq 20 \%$ \\
\hline & HER2 negative (HER2-) \\
\hline & Ki67<14\% \\
\hline \multirow[t]{4}{*}{ Luminal B (HER2-) } & Estrogen positive $(E R+)$ \\
\hline & HER2 negative (HER2-) \\
\hline & $\mathrm{Ki} 67 \geq 20 \%$ \\
\hline & $\begin{array}{l}\text { Progesterone receptor }(\mathrm{PR})<20 \% \text { or progester- } \\
\text { one receptor negative (PR-) }\end{array}$ \\
\hline \multirow[t]{4}{*}{ Luminal B (HER2+) } & Any progesterone receptor (PR) level \\
\hline & Any Ki67 level \\
\hline & HER2 positive (HER2+) \\
\hline & Estrogen positive $(\mathrm{ER}+)$ \\
\hline \multirow[t]{3}{*}{ HER2 positive (HER2+) (non-luminal) } & HER2 positive (HER2+) \\
\hline & Estrogen negative (ER-) \\
\hline & Progesterone negative (PR-) \\
\hline \multirow[t]{3}{*}{ Triple-negative breast cancer (TNBC) } & HER2 negative (HER2-) \\
\hline & Estrogen negative $(E R-)$ \\
\hline & Progesterone negative (PR-) \\
\hline
\end{tabular}

for inactivation or degradation. miRNAs play vital roles in multiple biological processes, such as development, cell proliferation and apoptosis. Aberrant expression of miRNAs is closely related with CSC maintenance and tumorigenesis [4]. This review focuses on roles of miRNAs in breast cancer progression, particularly their involvement in Wnt/ß-catenin, Notch, PI3K/AKT/ mTOR, BMI-1 and STAT3 pathways in breast cancer stem cells (BCSCs).

\section{Breast cancer stem cells}

BCSCs contribute to breast tumor initiation, malignancy and therapeutic resistance. They confer capability in differentiation and self-renewal $[6,7]$. Although they only account for approximately $2 \%$ breast tumor cells, BCSCs are mainly responsible for metastatic growth, high morbidity and mortality of BC. In addition, BCSCs could result in recurrence and relapse of $\mathrm{BC}$ due to their resistance to therapeutic treatments [8]. So far, despite the controversy, it is suggested that BCSCs originate from somatic and normal stem cells [9]. Several BCSC-specific biomarkers including CD44, CD24, aldehyde dehydrogenase (ALDH1) [10], epithelial specific antigen (ESA), CD326 (EpCAM) [11], CD133 [12], CD61 and CD49f [13] have been identified. These biomarkers are vital for BCSC isolation and potentially serve as therapeutic targets for $B C$ treatment.

\section{miRNA regulation of CSCs in breast cancer}

As mentioned above, miRNAs play critical roles in CSC differentiation and self-renewal. Emerging evidence suggests that miRNAs are also promising targets and powerful tools for therapeutic treatments of breast cancer via regulation of $\mathrm{BCSC}$ differentiation and self-renewal [1]. Here, we dissect and summarize the roles of BCSCsrelated miRNAs during breast cancer progression (Fig. 1).

miRNAs act as breast cancer suppressors (Table 2)

miR-7

miR-7 is expressed poorly in $\mathrm{CD}_{2} 4^{-} / \mathrm{CD} 44^{+} / \mathrm{ESA}^{+}$ BCSCs with potency to metastasize to brain and bone. It represses the brain but not bone metastasis of BCSCs by inversely regulating the expression of pluripotency marker KLF4 [14, 15]. Experiments performed in vitro revealed that miR-7 decreases BCSC's self-renewal and invasive ability by inhibiting the expression of KLF4 [14]. These results indicate that miR-7 and KLF4 may act as promising therapeutic targets and biomarkers for brain metastasis of $\mathrm{BC}$.

miR-93

miR-93 belongs to the miR106b-25 cluster and may function as a tumor suppressor, although it is frequently overexpressed in various human malignant cancers $[16,17]$. 


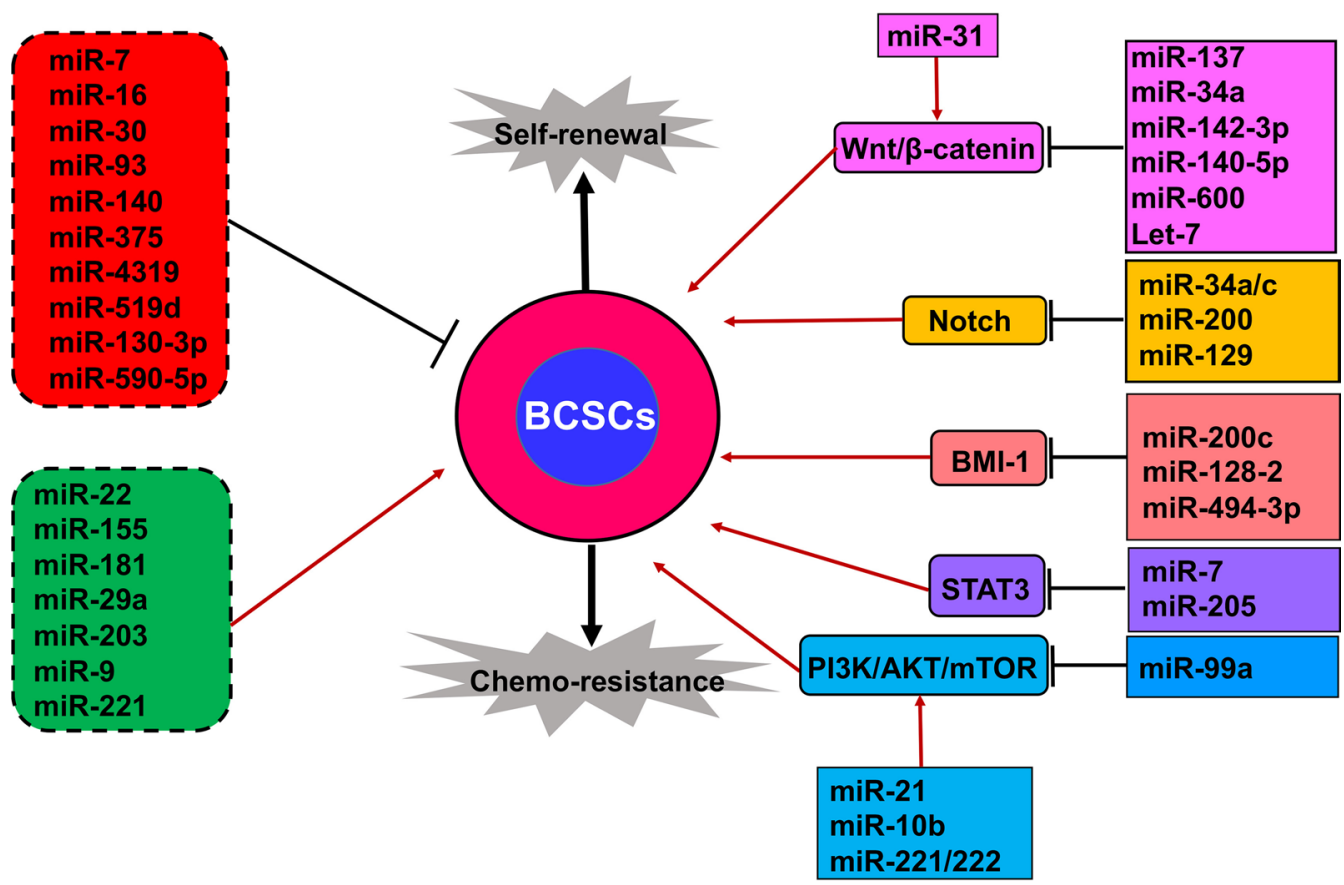

Fig. 1 miRNAs act as suppressors or oncomiRs in BCSC maintenance. miRNAs can both act as suppressors (red background) or oncomiRs (green background) to influence BCSC activities independently of known signaling pathways (left panel). On the other hand, some miRNAs can be placed into well-defined signaling pathways (right panel, different color backgrounds) by positively or negatively regulating the characteristics and development of BCSCs such as self-renewal or chemoresistance capacities

Table 2 miRNA acts as suppressor in breast cancer

\begin{tabular}{lll}
\hline miRNA & Target & Result on BCSCs \\
\hline miR-7 & KLF4 & Inhibits self-renewal, pluripotent potential metastatic and invasive ability of BCSCs \\
miR-93 & HMGA2 & \\
& AKT3 & \\
& EZH1 & Suppresses EMT and metastasis \\
& JAK1 & Inhibits differentiation and proliferation of BCSCs \\
& SOX4 & \\
miR-30 & STAT3 & \\
& UBC9 & Inhibits self-renewal ability of BCSCs \\
miR-590-5p & ITGB3 & Induces apoptosis of BCSCs \\
miR-140 & SOX2 & Inhibits stemness, metastasis, population and tumorigenicity of BCSCs \\
miR-16 & ALDH1 & Reduces stemness phenotypes of BCSCs \\
miR-130-3p & SOX9 & Inhibits tumor growth and formation in vivo \\
miR-4319 & Wip1 & Inhibits growth and self-renewal capacity of BCSCs \\
miR-519d & RAB5B & Represses proliferation, migration and invasion of BCSCs \\
miR-375 & E2F2 & Inhibits tumorigenicity and self-renewal of BCSCs \\
\hline & MCL-1 & Suppresses BCSCs' chemoresistance to cisplatin \\
& HOXB3 & Inhibits stemness phenotypes, EMT, migration and invasion of BCSCs
\end{tabular}

Expression of miR-93 downregulates multiple stem cell regulatory genes in BCSCs, including $H M G A 2, A K T 3$, EZH1, JAK1, SOX4 and STAT3, and ultimately leads to Mesenchymal-Epithelial Transition (MET). Mouse xenograft models reveal that ectopic expression of miR93 completely blocked the metastatic and tumor development abilities of BC. In addition, experiments with different breast cancer cell lines representing various 
differentiation states and mouse xenograft models reveal that miR-93 expression is lower in most undifferentiated and basal breast cancer cells, and that overexpression of miR-93 increases CSC population and tumor growth in more differentiated luminal breast cancer cells. These results suggest that miR-93 regulates the fate of BCSCs via controlling their differentiation and proliferation states [18].

\section{miR-30}

The miR-30 level is decreased in BCSCs, which is accompanied by increased expression of its target genes ITGB3 and $U B C 9$. Furthermore, miR-30 inhibits self-renewal and induces apoptosis of the BCSCs mainly through repressing these two targets. Moreover, a study using a BCSC xenograft mouse model demonstrates that overexpressed miR-30 reduces lung metastasis and tumorigenesis [19]. In addition, miR-30 modulates non-attachment growth and the expression of proliferation and apoptosis related genes in putative BCSCs, and is negatively associated with BC progression [20]. These findings suggest that miR-30 regulates the stemness of BCSCs to repress tumorigenesis and metastasis of $\mathrm{BC}$.

\section{miR-590-5p}

miR-590-5p is a potential target for breast cancer therapeutic treatments. It significantly reduces the population of BCSCs. In vivo NOD/SCID nude mice experiments reveal that miR-590-5p significantly inhibits tumorigenicity of BCs [21]. At the molecular level, miR-590-5p is able to repress the expression of a key stemness marker SOX2 and thus inhibits BCSCs' stemness and metastasis.

\section{miR-140}

Ductal carcinoma in situ (DCIS) is an early stage of BC and reducing the incidence of DCIS is the major goal of breast cancer prevention [22]. Volinia et al. found that miR-140 regulates BCSCs in luminal subtype invasive ductal carcinoma [23]. Li et al. demonstrated that loss of miR-140 is a hallmark of DCIS lesions and that miR-140 is significantly downregulated in BCSCs. They also found that restoration of miR-140 could decrease the expression of stem cell marker $A L D H 1$ and SOX9, and reduce basal-like breast tumor growth in vivo [24]. These results suggest that miR-140 is related to maintenance of basallike DCIS CSCs and deregulated stem cell signaling. Furthermore, miR-140/SOX9/ALDH1 axis is important for basal-like breast tumor formation, BCSCs' self-renewal and a potential therapy target for basal-like DCIS patients [24].

\section{miR-16}

To uncover the biological functions of miR-16 in the progression of breast cancer, Zhang et al. examined its expression in various $\mathrm{BCs}$ and $\mathrm{BCSCs}$, and found that miR-16 is significantly downregulated in BCSCs. Moreover, elevated expression of miR-16 inhibits the growth and self-renewal capacity of mouse mammary stem cells by inhibiting its target gene Wip1. More importantly, it confers MCF7 BC cells increased sensitivity to the chemotherapeutic drug doxorubicin [25].

\section{miR-130-3p}

miR-130-3p is downregulated in breast cancer cells and tissues. Overexpression of miR-130-3p in BCSCs inhibits cell proliferation by inducing G0/G1 arrest. Its elevation also represses $\mathrm{BC}$ cell migration and invasion by directly downregulating the expression of the oncogene $R A B 5 B$ [26]. Consistently, miR-130-3p depletion exhibits the opposite effects [26].

\section{miR-4319}

Upregulated miR-4319 markedly reduces the stemness and tumorigenicity of stem cells in triple-negative breast cancer (TNBC) via suppressing the expression of $E 2 F 2$, a transcription factor vital for stem cell self-renewal, while downregulation of miR-4319 promotes tumorsphere formation and self-renewal in TNBC CSCs and also promotes tumor initiation and metastasis in vivo [27].

\section{miR-519d}

miR-519d was found to be downregulated in BCSCs. The experimental expression of miR-519d enhances BCSCs' sensitivity to the chemotherapeutic drug cisplatin through an MCL-1 (an anti-apoptotic protein)-dependent mitochondria pathway [28]. Therefore, miR-519d could serve as a breast tumor suppressor by reducing chemoresistance in BCSCs.

\section{$\operatorname{miR}-375$}

The stemness of MCF7 cells can be suppressed by miR375. miR-375 also inhibited EMT, cell migration and invasion as well as tamoxifen-resistance by degrading its direct target $H O X B 3$ in human ER-positive breast cancers [29], indicating that targeting miR-375 and HOXB3 can be a promising therapeutic method for ER-positive breast cancer patients.

\section{miRNAs act as breast cancer oncogenes (Table 3)}

\section{$\operatorname{miR}-155$}

miR-155, also known as B-cell integration cluster (BIC), was first identified in B-cell lymphomas [30]. miR-155 is commonly overexpressed in multiple solid malignancies 
Table 3 miRNA acts as oncomiR in breast cancer

\begin{tabular}{lll}
\hline miRNA & Target & Result on BCSCs \\
\hline miR-155 & CD44 & Enhances BCSCs' chemoresistance to doxorubicin \\
& CD90 & \\
& ABCG2 & Promotes BCSCs'formation \\
miR-181 & BRCA1 & Increases stemness, colony formation and phenotypes of BCSCs \\
miR-22 & TET family & Increases stemness and metastasis of BCSCs \\
miR-29a & H4K20 & Promotes metastasis and invasion of BCSCs \\
miR-9 and miR221 & CD133 & Enhances stemness, proportion and tumor sphere formation of BCSCs \\
& Nanog & \\
miR-203 & OCt4 & Promotes proliferation, growth and self-renewal of BCSCs \\
\hline
\end{tabular}

besides breast cancer [31]. Inhibition of miR-155 markedly suppresses the formation of BCSCs by repressing the expression of stem cell markers CD44, CD90 and ABCG2. In addition, inhibition of miR-155 decreases proliferation of breast cancer cells and sensitizes MDAMB-231 BC cells to the chemotherapeutic drug Doxorubicinol. Taken together, miR-155 may be an oncomiR and a promising therapeutic target of breast cancer; it is also closely associated with sensitivity to chemotherapy and BCSC formation [31, 32].

\section{$\operatorname{miR}-181$}

miR-181 has been reported as an oncogenic miRNA. It promotes colony formation, self-renewal capacity and tumor development in breast cancer [5]. Transforming growth factor- $\beta$ (TGF- $\beta$ ) regulates the sphere-forming stem cell-like feature of BCSCs by upregulating miR-181 and downregulating ATM [33]. TGF- $\beta$ induces impaired DNA-repair efficiency and synthetic lethality to the inhibition of PARP by downregulating the DNA-repair gene BRCA1 through an miR-181-mediated mechanism in breast cancer. Furthermore, the miR181/BRCA1 axis plays a vital role in primary breast tumor by promoting CSC phenotypes [1, 34].

\section{miR-22}

Genetic and epigenetic alterations including altered miRNA expression are largely responsible for distantorgan metastasis of tumor cells. miR-22 promotes breast tumor metastasis via Ten eleven translocation (TET) family-dependent chromatin remodeling of $m i R-200$ and it eventually inhibited miR-200 activity [35]. miR-22 could expand the stem cell compartment and enhance mammary gland side-branching in a mammary glandspecific transgenic mouse model [35].

\section{miR-29a}

It was recently reported that miR-29a is increased in breast cancer tissues and BC cells like MCF7 and BCSCs [36]. miR-29a markedly inhibits the expression of $S U V 420 H 2$, encoding a histone methyltransferase that specifically trimethylates $\mathrm{H} 4 \mathrm{~K} 20$, via down-regulating histone H4K20 trimethylation and thus promotes BCSC metastatic capacities [36]. Moreover, miR-29a promotes breast cancer EMT via attenuating the repression of connective tissue growth factor (CTGF) and early growth response protein 1 (EGR1) by $\mathrm{H} 4 \mathrm{~K} 20$ trimethylation [36]. These findings collectively suggest that miR-29a is an oncomiR and is central for breast cancer EMT and metastasis via targeting BCSCs.

\section{miR-9 and miR-221}

It has been observed that overexpression of miR-9 and miR-221 dramatically increased BCSCs stemness, migration and invasion via increasing the number of side-population colonies with stem cell-like potency. Consistently, inhibition of miR-9 and miR-221 reduced the proportion and tumor-sphere formation of BCSCs by reducing the expression of the stemness markers Nanog, CD133 and Oct4. Moreover, increased levels of miR-9 and miR-221 in $\mathrm{BC}$ are closely related to elevated risk of progression to malignancy, poor differentiation, lymph-node metastasis, reduced survival, late-stage evolution and increased tumor size [37]. Hence, miR-9 and miR-221 have tumorigenic capacity as they promote $\mathrm{BCSCs}$ ' properties to yield an invasive phenotype in $\mathrm{BC}$.

\section{miR-203}

Upregulated expression of miR-203 was detected both in ER-positive $\left(\mathrm{ER}^{+}\right) \mathrm{BC}$ cell lines and $\mathrm{BC}$ tissues. Inhibition of miR-203 represses $\mathrm{ER}^{+}$breast cancer proliferation, growth and self-renewal capacity of BCSCs by negatively 
regulating suppressor of cytokine signaling 3 (SOCS3) expression [38]. These findings suggest that miR-203 serves as an oncomiR and may be a useful therapeutic target for $\mathrm{ER}^{+} \mathrm{BC}$ treatment.

\section{miRNA regulation of CSCs' signaling pathways in breast cancer \\ Roles of miRNAs in the Wnt/ $\beta$-catenin signaling pathway}

The Wnt/ $\beta$-catenin signaling pathway is important for CSC maintenance and closely associated with development of different cancers $[39,40]$. In the canonical Wnt/ $\beta$-catenin signaling pathway, there are two scenarios, "Wnt off" and "Wnt on." "Wnt off" refers to the absence of Wnt ligands, in which the destruction complex, consisting of APC (adenomatous polyposis coli), GSK-3 $\beta$ (glycogen synthase kinase 3 beta), Axin- 1 and CK1 $\alpha$ (casein kinase 1), is formed. This destruction complex modulates the cytoplasmic $\beta$-catenin level by phosphorylating $\beta$-catenin and targeting it for proteasomal degradation. "Wnt on" refers to the presence of Wnt ligands, which leads to Dvl (disheveled protein) phosphorylation via Wnt ligands binding to Frizzled/low density lipoprotein receptor-related proteins 5 or 6 (Lrp5/6). Dvl recruits Axin-1 to disrupt the destruction complex and stabilize $\beta$-catenin in the cytoplasm, which is translocated to the nucleus and binds to TCF4/LEF family transcription factors or other co-activators to activate target genes [41, 42] (Fig. 2). The Wnt pathway is highly activated in many type of CSCs [43].

It has been reported that some miRNAs regulate BCSC activities via the Wnt/ $\beta$-catenin pathway [44, 45] (Fig. 2), and the majority act as tumor suppressors. For example, FSTL1 (Follistatin Like 1) could increase breast cancer proliferation and stem cell marker expression, and it is closely associated with doxorubicin (DOX) and cisplatin (CDP) chemoresistance in breast cancer cells. Moreover, TOP-flash Wnt signaling luciferase activity assays confirmed that FSTL1 activates Wnt/ $\beta$-catenin signaling through integrin $\beta 3$ [46]. Furthermore, it was found that miR-137 directly targeted FSTL1 and reduced its mRNA and protein levels. Ultimately, their findings indicated that miR-137 inhibited the BCSCs' stemness and chemoresistance via inhibiting the Wnt $\beta$-catenin signaling pathway by directly downregulating FSTL1 expression [46].

miR-34a has potential to limit BCSC pools, and is critically associated with growth and maintenance of BCSCs and mammary gland stem cells by targeting the Wnt $/ \beta$-catenin signaling pathway. For instance, miR34a limits BCSCs self-renewal capacity by inhibiting the expression of several mesenchymal/basal BCSC markers like N-cadherin, vimentin, ITGA6 and keratin

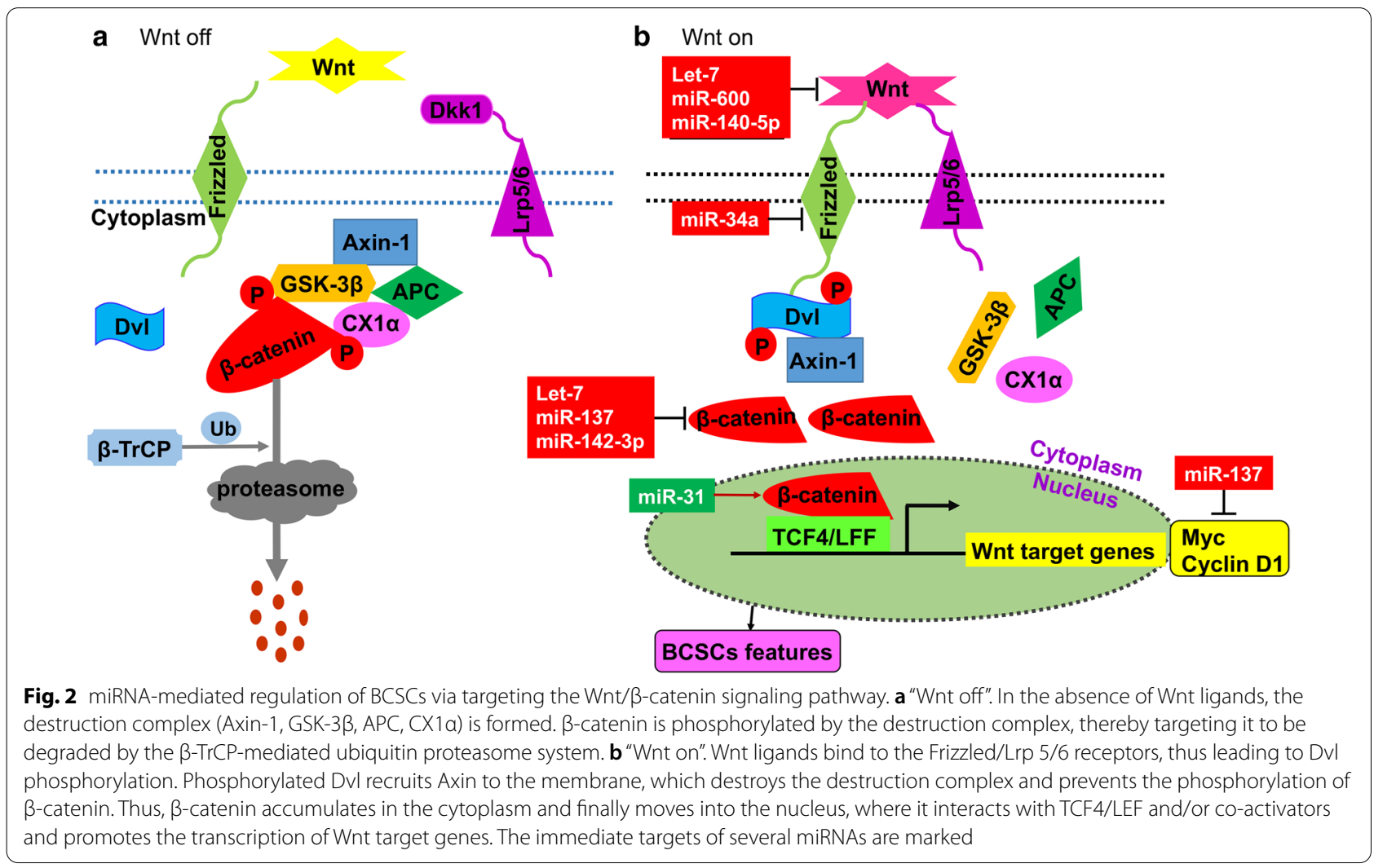


5 , and increasing the expression of CD24 (a marker of luminal differentiation) via inhibiting the $\mathrm{Wnt} / \beta$ catenin signaling through inhibiting multiple regulators of this pathway like Fzd1, Fzd2 and Pip5k1 $\alpha$. Thus, it would be an attractive strategy to control breast cancer via eradiation of BCSCs by targeting miR-34a-dependent $\mathrm{Wnt} / \beta$-catenin signaling [47].

Sun et al. used aldehyde dehydrogenase (ALDH1) sorting and mammosphere formation assays showed that miRNA Let-7 inhibited self-renewal of BCSCs in estrogen (ER)-positive breast cancer by blocking the ER activated Wnt/ $\beta$-catenin signaling pathway [48]. The results of their current study demonstrated that miRNA Let-7 decreases ratio and the self-renewal ability, contributing to reduced tumor formation capacity of BCSCs, and increased the anticancer functions of tamoxifen by suppressing ER and Wnt/ $\beta$-catenin signaling [49]. Hence, Let-7 has tumor suppressive functions and could enhance endocrine therapy by modulating the stemness of ER-treated CSCs in breast cancer.

It was reported that overexpressed miR-142-3p is accompanied by decreased expression of stem cell makers CD44, CD133, ALDH1, BRCA2, Bod1 and $\beta$-catenin levels in $B C$. It inhibits mammosphere formation, radiation tolerance and BCSC features of $\mathrm{BC}$ cells [50]. Thus, miR-142-3p appears to suppress BCSC characteristics and radioresistance by inhibiting the Wnt/ $\beta$-catenin pathway.

miR-140-5p is commonly considered a tumor suppressor through interaction with stem cell regulators SOX9, SOX2 and Wnt in early stage breast cancer. Consistently, overexpressed miR-140-5p could decrease BCSC populations and inhibit breast cancer progression via suppressing these pathways [51]. Furthermore, miR-140-5p could inhibit BCSC proliferation, tumorsphere formation and sensitize BCSCs to doxorubicin by downregulating the $\mathrm{Wnt} / \beta$-catenin signaling pathway [52].

Overexpression of miR-600 could attenuate BCSCs' self-renewal ability, decrease tumorigenicity in vivo and promote BCSC differentiation via targeting stearoyl desaturase-1 (SCD1), an enzyme required to produce active, lipid-modified Wnt proteins, by inhibiting the Wnt/ $\beta$-catenin signaling pathway [53].

It has been demonstrated that miR-31 is upregulated in mammary tumors and mammary stem cells (MaSCs) and can enhance MaSC expansion and mammary epithelial proliferation; knocking out miR-31 inhibited breast tumor growth, decreased BCSC populations, tumor-initiating ability and metastasis to lung by activating Wnt antagonist Dkk1 and eventually suppressing the Wnt/ $\beta$ catenin signaling pathway [54]. To date, miR-31 is the only reported oncomiR in the $\mathrm{Wnt} / \beta$-catenin pathway.

\section{Roles of miRNAs in the Notch signaling pathway}

The Notch signaling is a primordial, evolutionally conserved pathway closely associated with cancer stem cell maintenance [55]. Dysregulation of this pathway occurs frequently in different types of human cancers, including breast cancer [56]. The Notch signaling pathway consists of three components: Notch ligands (DLL1, DLL3, DLL4, Jagged-1 and Jagged-2), Notch receptors (Notch-1, 2, 3 and 4) and the DNA binding sequence CSL. When a Notch ligand on one cell interacts with a Notch receptor on an adjacent cell, it liberates a Notch receptor intracellular domain (NICD), which can be recognized by ADAMs (a disintegrin and metalloproteases) and $\gamma$-secretase, respectively. The liberated NICD is translocated into the nucleus and binds to CSL, leading to corresponding transcription of downstream genes [57] (Fig. 3).

The Notch signaling regulates the self-renewal of CSCs. Members of the miR-34 family are considered tumor-suppressors and are associated with multiple human cancers. Overexpressed miR-34a reduces BCSC stemness, chemoresistance to doxorubicin and inhibits tumor formation by directly inhibiting Notch1 [58]. Furthermore, miR-34a is reduced in BCSCs. Increased miR-34a expression suppresses the Notch signaling pathway and subsequently inhibits breast cancer cell proliferation, migration, invasion, chemoresistance to paclitaxel (PTX) and BCSC propagation [59]. Additionally, miR-34c, another miR-34 family member, is downregulated in breast tumor-initiating cells (BT-ICs, also known as BCSCs), while overexpression of miR-34c in BC cells dramatically inhibited EMT, migration and self-renewal of BT-ICs via silencing its target gene Notch4 [60]. Therefore, the miR-34 family (miR-34a/c) could serve as a promising target for prevention and therapy of breast cancer. Similarly, miR-200 family miRNAs are downregulated in BCSCs, and they inhibit BCSCs functions probably through suppressing Notch signaling by targeting Notch pathway components such as JAG1 and the mastermind-like Notch co-activators Maml2 and Maml3 [42].

On the other hand, miR-129 inhibits breast cancer cell's self-renewal by suppressing Let-7b expression through directly inhibiting Estrogen Receptor 1 (ESR1). The decreased Let- $7 \mathrm{~b}$ releases its targeted inhibition of NUMB homologue and blocks the Notch oncogenic signaling [61] (Fig. 3).

\section{Roles of miRNAs in the PI3K/AKT/mTOR signaling pathway}

The PI3K/AKT/mTOR signaling pathway is involved in the function and drug resistance of BCSCs [62]. Dysregulation of the $\mathrm{PI} 3 \mathrm{~K} / \mathrm{AKT} / \mathrm{mTOR}$ pathway are very common in many types of human cancers, including breast cancer [63]. Phosphatidylinositol 3-kinases (PI3K) can be activated by receptor tyrosine kinases (RTKs), 


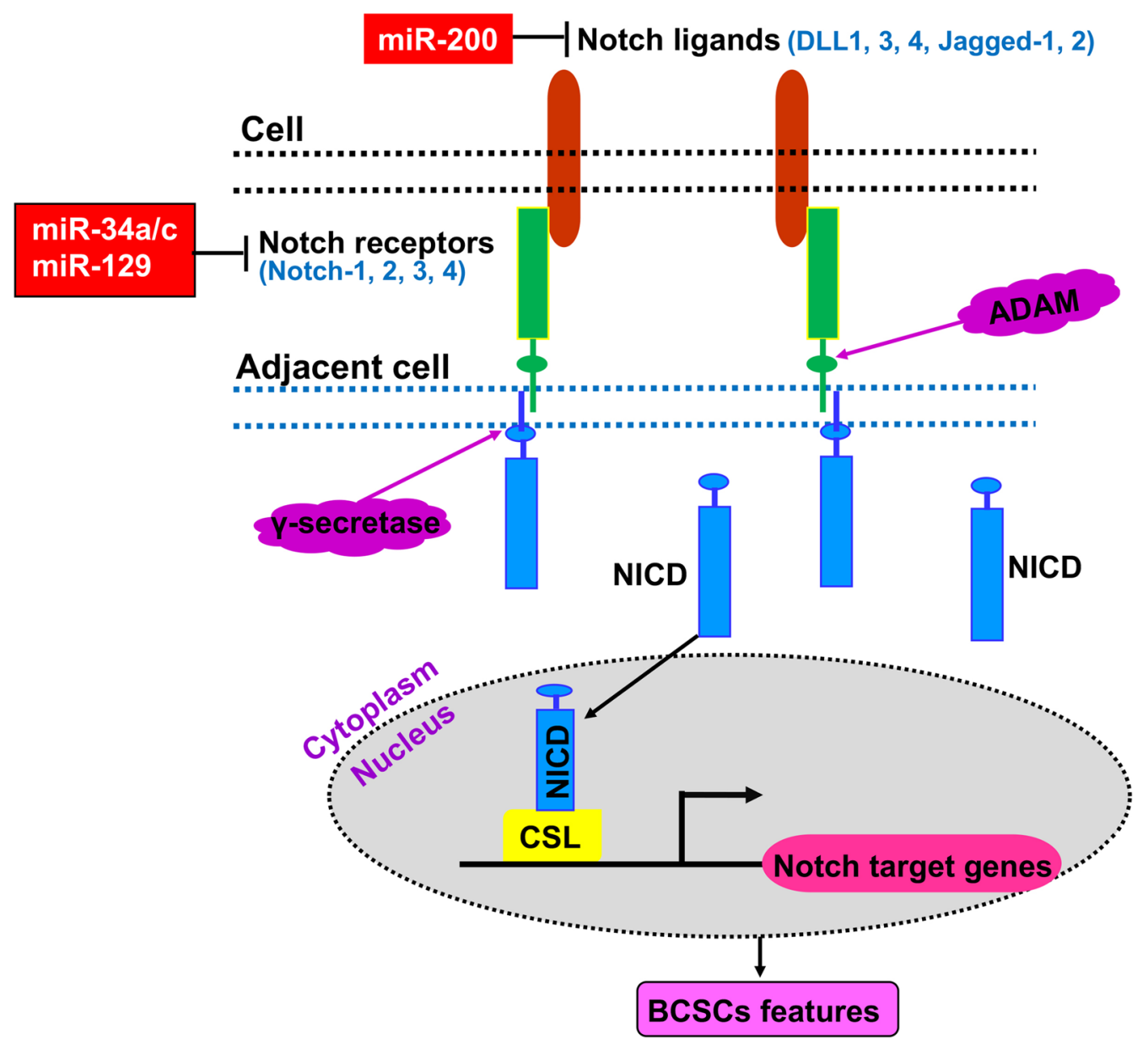

Fig. 3 miRNA-mediated regulation of BCSCs via targeting the Notch signaling pathway. The Notch signaling pathway is activated when Notch ligands on one cell interact with Notch receptors on an adjacent cell, resulting in the two consecutive cleavages of Notch receptors by ADAMs and $\gamma$-secretase, and the release of Notch receptor intracellular domain NICD into the cytoplasm. The released NICD is translocated into the nucleus and binds to CSL to initiate the Notch target genes' expression. The immediate targets of related miRNAs are marked

integrins, $\mathrm{B}$ and $\mathrm{T}$ cell receptors, cytokine receptors and GPCRs, leading to phosphatidylinositol 4, 5 bisphosphate (PIP2) to be phosphorylated to phosphatidylinositol 3, 4, 5 trisphosphate (PIP3) and the generation of PIP3 in the plasma membrane. PIP3 then interacts with the PH domain of AKT and recruits AKT to the cell membrane. Next, phosphoinositide-dependent kinase-1 (PDK1) phosphorylates AKT at the Thr308 residue and activates AKT [64]. PTEN (Phosphatase and tensin homolog) dephosphorylates PIP3 to form PIP2, and is the most important negative regulator of AKT and an antagonist of PI3K. Mammalian target of rapamycin (mTOR) is not only a downstream member but also an activator of AKT; it can phosphorylate AKT at Ser473, facilitate its Thr308 phosphorylation by PDK1 and fully activate AKT [65] (Fig. 4). Recently, some studies reported that miRNAs regulate cancer progression through this pathway $[66,67]$ (Fig. 4).
miR-99a is found downregulated in a population of breast cancer stem-like cells known as SP cells. miR-99a suppresses SP self-renewal and tumorigenicity in vivo, and migration and invasion in vitro via suppressing the expression of $m T O R$ [68], suggesting that miR99a directly represses PI3K/AKT/mTOR signaling and reverses the phenotypes of BCSCs.

On the other hand, several miRNAs have been found to activate the PI3K/AKT signaling pathway through targeting PTEN. For example, miR-10b increases expression of stemness and EMT markers and promotes the selfrenewal of BCSCs through repressing the transcription of PTEN [69]. Similarly, ectopic expression of miR-221/222 promotes breast cancer cell proliferation, migration, invasion, enriched proportion of CD44(+)/CD24(-) BCSCs and improves mammosphere formation capacity via downregulating PTEN [70]. Finally, antagomir-mediated interference of miR-21 activates PTEN expression, 


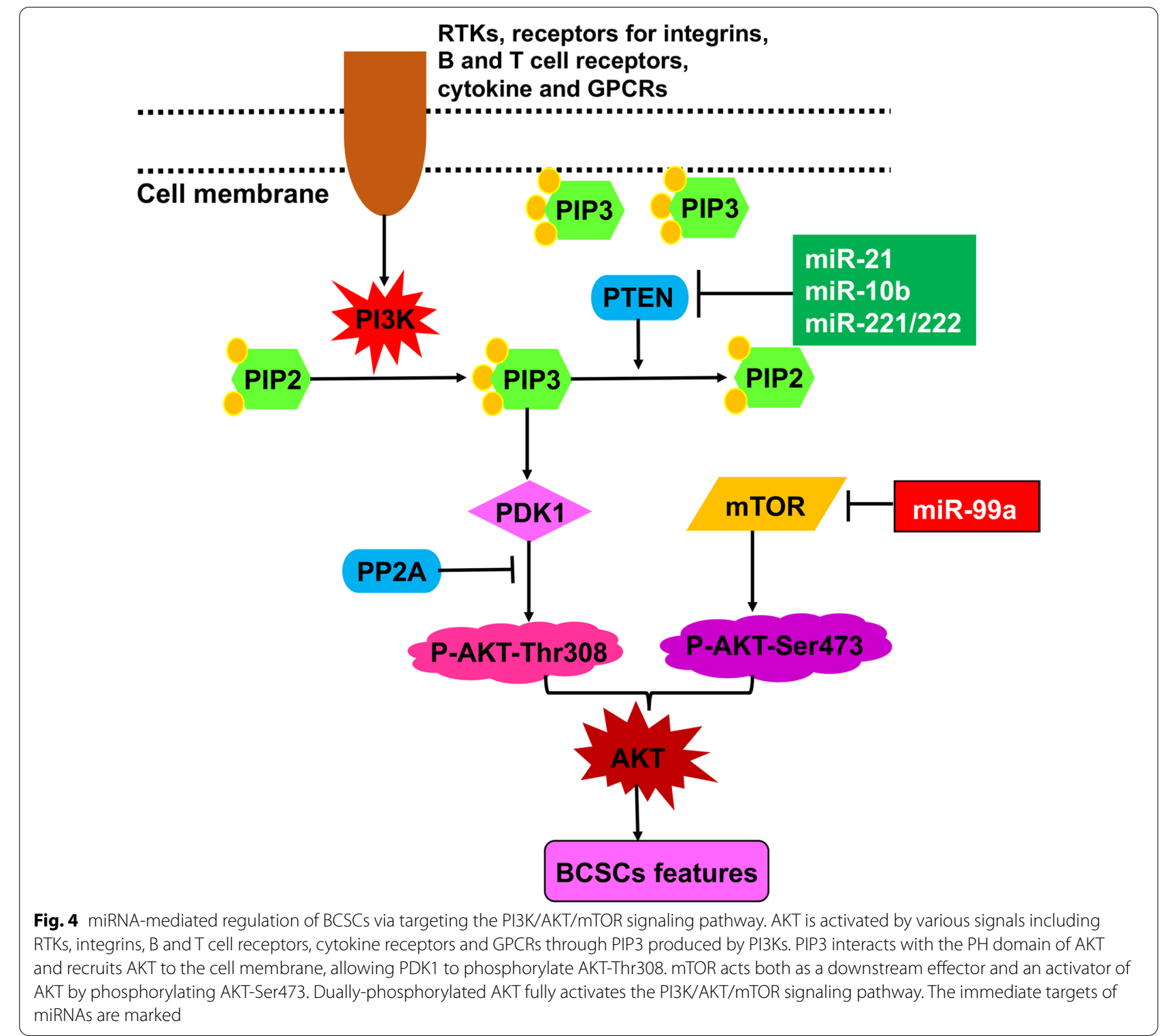

and thus reverses EMT, reduces migration and invasion in breast cancer cells, and decreases BCSC self-renewal capacity and clonogenicity [71].

\section{Roles of miRNAs in the BMI-1 signaling pathway}

BMI-1 (B lymphoma Mo-MLv insertion region 1 homolog) is a component of the polycomb repression complex 1 (PRC1). It acts as a self-renewal regulator to prevent senescence and apoptosis in normal and CSCs [72]. To support BMI-1-mediated self-renewal, PRC1 suppresses the Ink4a locus that encodes $p 16^{\text {Ink4a }}$ and p19 ${ }^{\text {Arf }}$ genes by trimethylation of H3-K27 (H3K27me3) and ubiquitination of H2A-K119 (H2AK119Ub). Moreover, $p 16^{\text {Ink4a }}$ and $p 19^{\text {Arf }}$ are regulators of immortalization and senescence. Deletion and mutations of these two genes are frequently found in human cancers. The deubiquitinating enzyme USP16 suppresses self-renewal and senescence pathways in multiple tissues via deubiquitinating H2AK119 and increasing Ink4a locus transcription [73], while BMI-1 regulates cell cycle, apoptosis and senescence via inhibiting $p 16^{\text {Ink4a }}$ and $p 19^{\text {Arf }}$ genes encoded by Ink4a [74, 75]. BMI-1 is found to be upregulated in various human BC cells and is essential for self-renewal of BCSCs via suppressing genes involved in apoptosis and senescence [76] (Fig. 5).

The expression of $B M I-1$ is modulated by some miRNAs in human cancers [77-79] (Fig. 5). For instance, miR-200b, miR-200c, miR-183 and miR-141 are 


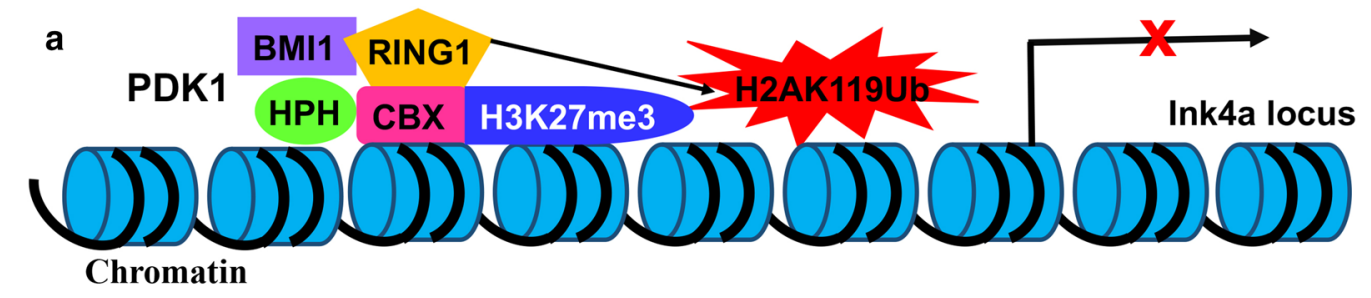

b

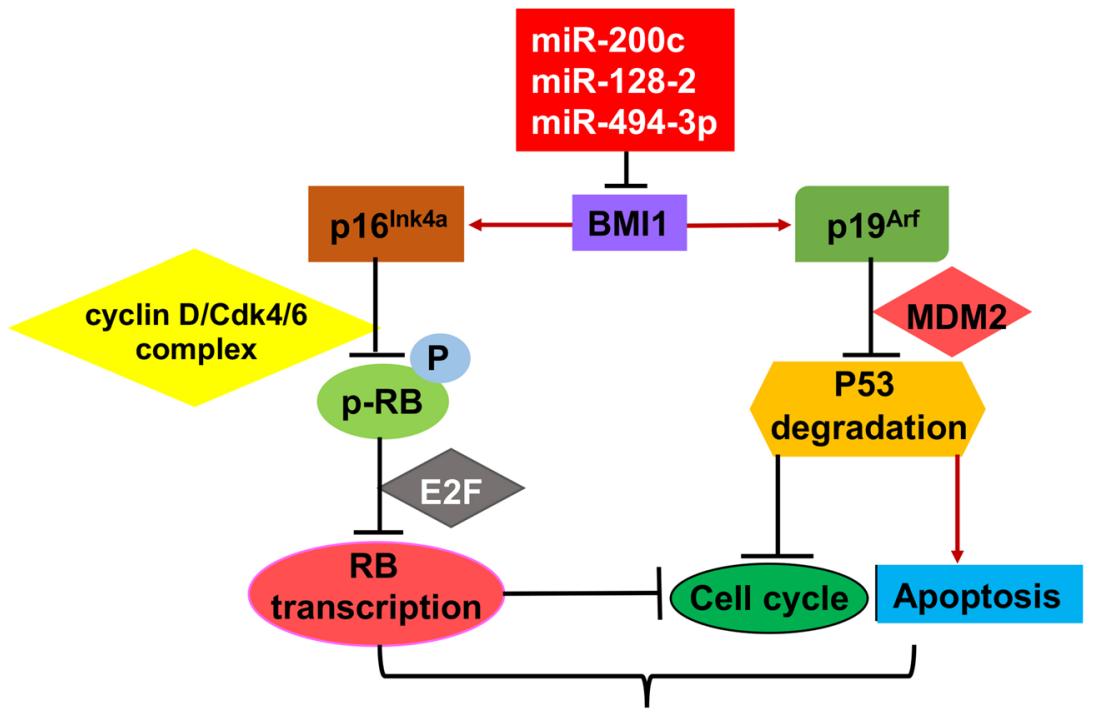

BCSCs features

Fig. 5 miRNA-mediated regulation of the BCSCs via targeting the BMI-1 signaling pathway. a To support self-renewal of stem cells by BMI-1 (a component of PRC1), PRC1 suppresses the expression of the Ink4a locus that encodes the $p 16^{\text {Ink4a }}$ and the $p 19^{\text {Arf }}$ genes by trimethylation of H3-K27 (H3K27me3) and ubiquitination of H2A-K119 (H2AK119Ub). The chromodomain of CBX binds to H3K27me3 and RING1 deposits monoubiquitin on H2AK119. $\mathbf{b}$ p $16^{\text {Ink4a }}$ inhibits the phosphorylation of RB by the cyclin D/Cdk4/6 complex and E2F-dependent transcription of RB that finally inhibit cell cycle progression. $19^{\text {Arf }}$ causes high levels of p53 via preventing MDM2-mediated p53 degradation, which represses cell cycle progression and promotes apoptosis. The immediate targets of miRNAs are marked

dramatically downregulated in normal mammary stem cells and BCSCs, suggesting that the miR-200 family members play vital roles in regulating the self-renewal of BCSCs and normal mammary stem cells. Via downregulating BMI-1, miR-200c inhibits BC cell growth, induces cell differentiation and suppresses tumor formation in vivo. More importantly, it strongly suppresses the ability of normal mammary stem cells to form mammary ducts and suppresses tumor formation driven by human BCSCs in vivo [80, 81].

On the other hand, ectopic expression of miR-128 in BCSCs suppresses breast cancer progression and induces apoptosis by downregulating BMI-1 and ABCC5 expression [82]. In addition, the tropolonerelated compound Hinokitiol is known to have an anti-cancer effect $[83,84]$. It was found that Hinokitiol upregulates miR-494-3p to repress self-renewal of BCSCs via inhibiting BMI-1 expression [85].

\section{Roles of miRNAs in the STAT3 signaling pathway}

Signal Transducer and Activator of Transcription 3 (STAT3) is not only a transcription factor that plays a vital role in the biology of transformed and normal cells but also an important regulator of normal and BCSCs. It has six functional domains, including an $\mathrm{N}$-terminal domain (NTD), a coiled coil domain (CCD) that mediates protein-protein interactions, a DNA-binding domain (DBD), a linker domain (LD), an SH2 (SRC homology 2) domain and a $\mathrm{C}$-terminal transcription activation domain (TAD). It also has two important phosphorylation sites: Tyr705 within the SH2 domain, and Ser727 within TAD $[86,87]$. STAT3 is mainly activated by phosphorylation of the conserved Tyr705 residue, which leads to its dimerization [88]. The activated STAT3 dimers interact with importins, translocate into the nucleus and activate target genes by binding to their GAS (interferon- $\gamma$-activated sequence) motifs [86, 89-91] (Fig. 6). 
a

\begin{tabular}{l|l|l|l|l|l|l|}
\hline STAT3 & NTD & CCD & DBD & LD & SH2 & TAD \\
\hline
\end{tabular}

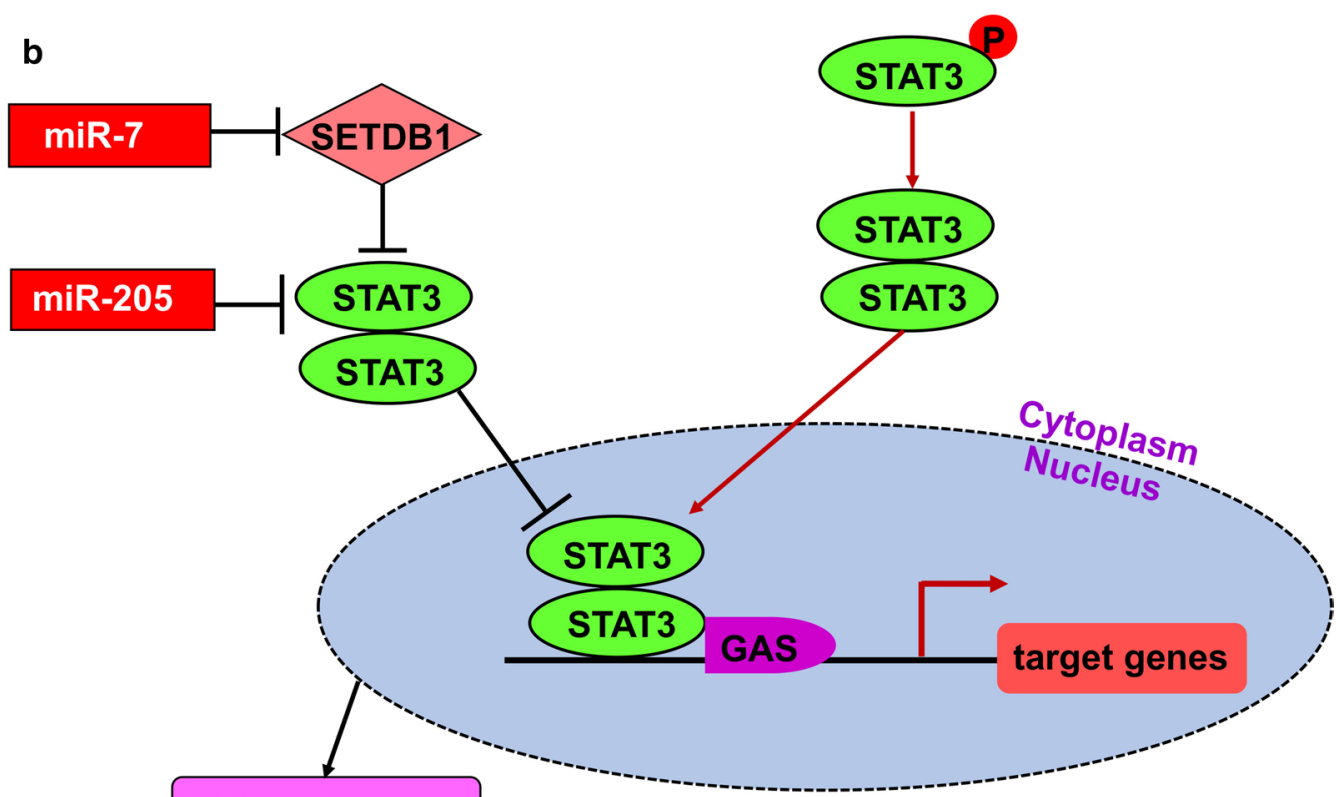

BCSCs features

Fig. 6 miRNA-mediated regulation of BCSCS via targeting the STAT3 signaling pathway. a STAT3 has six functional domains and two phosphorylation sites, as indicated. b STAT3 is mainly activated by Tyr705 phosphorylation within the SH2 domain, which leads to its dimerization. Activated STAT3 dimers interact with importins, translocate into the nucleus and activate target gene transcription by binding to the GAS motif of target genes. The immediate targets of miRNAs are marked

Several studies revealed that miRNAs are critical regulators of STAT3 in many types of human cancers [92] (Fig. 6). For instance, miR-7 inhibits metastasis and population growth, reverses EMT of BCSCs via directly suppressing oncogene SETDB1. Since SETDB1 transcriptionally activates the expression of STAT3, miR-7-mediated SETDB1 repression downregulates the STAT3 signaling pathway [93]. miR-205 is thought to be not only a tumor suppressor but also an oncomiR in breast cancer [94]. As a suppressor, ectopic expression of miR-205 inhibits cell anchorage-independent growth and proliferation by repressing expression of ErbB3, which is a component of the most potent oncogenic complex ErbB2/ ErbB3 heterodimer in breast cancer [95]. Moreover, miR205 inhibits breast cancer invasion by directly targeting the key angiogenesis regulator VEGF-A [95]. As an oncomiR, miR-205 promotes the colony-forming potential of mammary epithelial cells and leads to an expansion of the progenitor-cell population by targeting the tumor suppressor gene phosphatase and tensin homolog (PTEN) [96]. It also has been shown to play an important role in the maintenance of BCSCs via inhibiting CSC selfrenewal capacity and suppressing expression of stem cell markers CD44, ALDH1, TAZ and E2Q-E12, most likely through regulating STAT3 signaling [97].

\section{Conclusion and future perspective}

It is now well-established that breast cancer harbors a small population of BCSCs, which are considered major oncogenic driving cells, as they facilitate breast tumor metastasis, relapse, progression and confer breast cancer therapy resistance by bestowing abilities such as migration, invasion, sphere formation, pluripotency, low-proliferation rate, self-renewal and tumor-initiation [4]. Hence, they play important roles in the resistance to therapeutic agents and the development of tumor heterogeneity by contributing to the propagation of neoplastic cells.

Although multiple mechanisms have been associated with stemness maintenance and BCSC functions attributed to the oncogenic potential, there are still unanswered questions calling for further investigation. Recent development in breast cancer research has revealed that miRNAs are promising therapeutic targets for breast cancer via their driving oncogenic potential and therapeutic hindrance due to BCSCs. Indeed, they are deregulated in various 
pathological conditions including CSCs during cancer progression.

In this review, we summarized recent advances for the roles of various miRNAs in a few BCSC-related signaling pathways important for maintenance of CSCs during breast cancer progression. Hence, targeting miRNAs is central for the elimination of BCSCs and breast cancer recurrence, therapeutic resistance and metastasis as miRNAs play regulatory roles in various characteristics of BCSCs.

In the future, therapeutic potentials could be further explored in breast cancer cells expressing an aberrant level of miRNAs. Several miRNA-based analogs and antagonists are currently being investigated and under clinical trials. For example, MRX34 (Mirna Therapeutics, Inc., Austin, TX, USA) is a liposomal product designed to deliver an analog of the naturally occurring tumor suppressor miR-34 [98], whereas most miRNAs are still explored at subclinical animal experimental levels and their therapeutics are still in infancy. Taken together, remarkable development and efforts are needed to bring the miRNA-based therapy from labs to the clinic.

\section{Acknowledgements}

We wish to thank Michelle Hanna for proofreading the manuscript.

\section{Authors' contributions}

TN made literature search and drafted the manuscript of this review. WX supervised the work and revised the manuscript. WX and WZ edited the manuscript. All authors read and approved the final manuscript.

\section{Funding}

This work was supported by the National Natural Science Foundation of China operating grant 81872003 to WZ and the Canadian Breast Cancer Foundation research grant C7022 to WX.

\section{Availability of data and materials}

Not applicable.

\section{Ethics Approval and consent to participate}

Not applicable.

\section{Consent for publication}

All authors agree with the final version of the manuscript and give their consent for its publication.

\section{Competing interest}

The authors declare that they have no competing interests.

\section{Author details}

1 Beijing Key Laboratory of DNA Damage Responses and College of Life Sciences, Capital Normal University, Beijing 100048, China. ${ }^{2}$ Department of Biochemistry, Microbiology and Immunology, University of Saskatchewan, Saskatoon, SK S7N 5E5, Canada.

Received: 25 October 2020 Revised: 7 December 2020 Accepted: 16 December 2020

Published online: 07 January 2021

\section{References}

1. Yousefnia S, Seyed Forootan F, Seyed Forootan S, Nasr Esfahani MH, Gure AO, Ghaedi K. Mechanistic pathways of malignancy in breast cancer stem cells. Front Oncol. 2020;10:452
2. Gao JJ, Swain SM. Luminal A breast cancer and molecular assays: a review. Oncologist. 2018;23(5):556-65.

3. Dong H, Diao H, Zhao Y, Xu H, Pei S, Gao J, Wang J, Hussain T, Zhao D, Zhou $X$, et al. Overexpression of matrix metalloproteinase-9 in breast cancer cell lines remarkably increases the cell malignancy largely via activation of transforming growth factor beta/SMAD signalling. Cell Proliferation. 2019;52(5):e12633.

4. Asadzadeh Z, Mansoori B, Mohammadi A, Aghajani M, Haji-Asgarzadeh K, Safarzadeh E, Mokhtarzadeh A, Duijf PHG, Baradaran B. microRNAs in cancer stem cells: biology, pathways, and therapeutic opportunities. J Cell Physiol. 2019;234(7):10002-17.

5. Khan AQ, Ahmed El, Elareer NR, Junejo K, Steinhoff M, Uddin S. Role of miRNA-regulated cancer stem cells in the pathogenesis of human malignancies. Cells. 2019:8(8):840.

6. Mathieu J, Ruohola-Baker H. Regulation of stem cell populations by microRNAs. Adv Exp Med Biol. 2013;786:329-51.

7. Morel AP, Lièvre M, Thomas C, Hinkal G, Ansieau S, Puisieux A. Generation of breast cancer stem cells through epithelial-mesenchymal transition. PloS One. 2008;3(8):e2888.

8. Lin CY, Barry-Holson KQ, Allison KH. Breast cancer stem cells: are we ready to go from bench to bedside? Histopathology. 2016;68(1):119-37.

9. Sin WC, Lim CL. Breast cancer stem cells-from origins to targeted therapy. Stem Cell Investig. 2017;4:96.

10. de Beça FF, Caetano P, Gerhard R, Alvarenga CA, Gomes M, Paredes J, Schmitt F. Cancer stem cells markers CD44, CD24 and ALDH1 in breast cancer special histological types. J Clin Pathol. 2013;66(3):187-91.

11. Baeuerle PA, Gires O. EpCAM (CD326) finding its role in cancer. Br J cancer. 2007;96(3):417-23.

12. Liu TJ, Sun BC, Zhao XL, Zhao XM, Sun T, Gu Q, Yao Z, Dong XY, Zhao N, Liu N. CD133 + cells with cancer stem cell characteristics associates with vasculogenic mimicry in triple-negative breast cancer. Oncogene. 2013;32(5):544-53.

13. Lo PK, Kanojia D, Liu X, Singh UP, Berger FG, Wang Q, Chen H. CD49f and CD61 identify Her2/neu-induced mammary tumor-initiating cells that are potentially derived from luminal progenitors and maintained by the integrin-TGFbeta signaling. Oncogene. 2012;31(21):2614-26.

14. Okuda H, Xing F, Pandey PR, Sharma S, Watabe M, Pai SK, Mo YY, liizumi-Gairani M, Hirota S, Liu Y, et al. miR-7 suppresses brain metastasis of breast cancer stem-like cells by modulating KLF4. Cancer Res. 2013;73(4):1434-44

15. van Schaijik B, Davis PF, Wickremesekera AC, Tan ST, Itinteang T. Subcellular localisation of the stem cell markers OCT4, SOX2, NANOG, KLF4 and C-MYC in cancer: a review. J Clin Pathol. 2018;71(1):88-91.

16. Ibarra I, Erlich Y, Muthuswamy SK, Sachidanandam R, Hannon GJ. A role for microRNAs in maintenance of mouse mammary epithelial progenitor cells. Genes Dev. 2007;21(24):3238-43.

17. Petrocca F, Vecchione A, Croce CM. Emerging role of miR-106b-25/miR17-92 clusters in the control of transforming growth factor beta signaling Cancer Res. 2008;68(20):8191-4.

18. Liu S, Patel SH, Ginestier C, Ibarra I, Martin-Trevino R, Bai S, McDermott SP, Shang L, Ke J, Ou SJ, et al. MicroRNA93 regulates proliferation and differentiation of normal and malignant breast stem cells. PLoS Genet. 2012;8(6):e1002751.

19. Yu F, Deng H, Yao H, Liu Q, Su F, Song E. Mir-30 reduction maintains selfrenewal and inhibits apoptosis in breast tumor-initiating cells. Oncogene. 2010;29(29):4194-204.

20. Ouzounova M, Vuong T, Ancey PB, Ferrand M, Durand G, Le-Calvez Kelm F, Croce C, Matar C, Herceg Z, Hernandez-Vargas H. MicroRNA miR-30 family regulates non-attachment growth of breast cancer cells. BMC Genomics. 2013;14:139.

21. Zhou L, Zhao LC, Jiang N, Wang XL, Zhou XN, Luo XL, Ren J. MicroRNA miR-590-5p inhibits breast cancer cell stemness and metastasis by targeting SOX2. Eur Rev Med Pharmacol Sci. 2017;21(1):87-94.

22. Leonard GD, Swain SM. Ductal carcinoma in situ, complexities and challenges. J Natl Cancer Inst. 2004;96(12):906-20.

23. Volinia S, Galasso M, Sana ME, Wise TF, Palatini J, Huebner K, Croce CM. Breast cancer signatures for invasiveness and prognosis defined by deep sequencing of microRNA. Proc Natl Acad Sci USA. 2012;109(8):3024-9.

24. Li Q, Yao Y, Eades G, Liu Z, Zhang Y, Zhou Q. Downregulation of miR-140 promotes cancer stem cell formation in basal-like early stage breast cancer. Oncogene. 2014;33(20):2589-600. 
25. Zhang X, Wan G, Mlotshwa S, Vance V, Berger FG, Chen H, Lu X. Oncogenic Wip1 phosphatase is inhibited by miR-16 in the DNA damage signaling pathway. Cancer Res. 2010;70(18):7176-86.

26. Kong X, Zhang J, Li J, Shao J, Fang L. MiR-130a-3p inhibits migration and invasion by regulating RAB5B in human breast cancer stem cell-like cells. Biochem Biophys Res Commun. 2018;501(2):486-93.

27. Chu J, Li Y, Fan X, Ma J, Li J, Lu G, Zhang Y, Huang Y, Li W, Huang X, et al. MiR-4319 suppress the malignancy of triple-negative breast cancer by regulating self-renewal and tumorigenesis of stem cells. Cell Physiol Biochem. 2018;48(2):593-604.

28. Xie Q, Wang S, Zhao Y, Zhang Z, Qin C, Yang X. MiR-519d impedes cisplatin-resistance in breast cancer stem cells by down-regulating the expression of MCL-1. Oncotarget. 2017;8(13):22003-13.

29. Fu H, Fu L, Xie C, Zuo WS, Liu YS, Zheng MZ, Yu JM. miR-375 inhibits cancer stem cell phenotype and tamoxifen resistance by degrading HOXB3 in human ER-positive breast cancer. Oncol Rep. 2017;37(2):1093-9.

30. Le Quesne J, Caldas C. Micro-RNAs and breast cancer. Molecular Oncol. 2010;4(3):230-41.

31. Jiang $\mathrm{S}$, Zhang HW, Lu MH, He XH, Li Y, Gu H, Liu MF, Wang ED. MicroRNA-155 functions as an OncomiR in breast cancer by targeting the suppressor of cytokine signaling 1 gene. Cancer research. 2010;70(8):3119-27.

32. Zuo J, Yu Y, Zhu M, Jing W, Yu M, Chai H, Liang C, Tu J. Inhibition of miR155, a therapeutic target for breast cancer, prevented in cancer stem cell formation. Cancer Biomark A. 2018;21(2):383-92.

33. Wang Y, Yu Y, Tsuyada A, Ren X, Wu X, Stubblefield K, Rankin-Gee EK, Wang SE. Transforming growth factor-beta regulates the sphere-initiating stem cell-like feature in breast cancer through miRNA-181 and ATM. Oncogene. 2011;30(12):1470-80.

34. Liu L, Zhou W, Cheng CT, Ren X, Somlo G, Fong MY, Chin AR, Li H, Yu $Y, X u Y$, et al. TGF $\beta$ induces "BRCAness" and sensitivity to PARP inhibition in breast cancer by regulating DNA-repair genes. Mol Cancer Res. 2014;12(11):1597-609.

35. Song SJ, Poliseno L, Song MS, Ala U, Webster K, Ng C, Beringer G, Brikbak NJ, Yuan X, Cantley LC, et al. MicroRNA-antagonism regulates breast cancer stemness and metastasis via TET-family-dependent chromatin remodeling. Cell. 2013;154(2):311-24.

36. Wu Y, Shi W, Tang T, Wang Y, Yin X, Chen Y, Zhang Y, Xing Y, Shen Y, Xia T, et al. miR-29a contributes to breast cancer cells epithelial-mesenchyma transition, migration, and invasion via down-regulating histone H4K2O trimethylation through directly targeting SUV420H2. Cell Death Dis. 2019;10(3):176.

37. Cheng CW, Yu JC, Hsieh YH, Liao WL, Shieh JC, Yao CC, Lee HJ, Chen PM, Wu PE, Shen CY. Increased cellular levels of microRNA-9 and microRNA-221 correlate with cancer stemness and predict poor outcome in human breast cancer. Cell Physiol Biochem. 2018;48(5):2205-18.

38. Muhammad N, Bhattacharya S, Steele R, Ray RB. Anti-miR-203 suppresses ER-positive breast cancer growth and stemness by targeting SOCS3. Oncotarget. 2016;7(36):58595-605.

39. Duchartre Y, Kim YM, Kahn M. The Wnt signaling pathway in cancer. Crit Rev Oncol Hematol. 2016:99:141-9.

40. Jang GB, Kim JY, Cho SD, Park KS, Jung JY, Lee HY, Hong IS, Nam JS. Blockade of Wnt/ $\beta$-catenin signaling suppresses breast cancer metastasis by inhibiting CSC-like phenotype. Sci Rep. 2015;5:12465.

41. Vallée A, Lecarpentier Y, Vallée JN. Targeting the canonical WNT/ß-catenin pathway in cancer treatment using non-steroidal anti-inflammatory drugs. Cells. 2019;8(7):726.

42. Zhang $Y, X u B$, Zhang XP. Effects of miRNAs on functions of breast cancer stem cells and treatment of breast cancer. OncoTargets therapy. 2018:11:4263-70.

43. Katoh M, Katoh M. WNT signaling pathway and stem cell signaling network. Clin Cancer Res. 2007;13(14):4042-5.

44. Huang K, Zhang JX, Han L, You YP, Jiang T, Pu PY, Kang CS. MicroRNA roles in beta-catenin pathway. Mol Cancer. 2010;9:252.

45. Xing F, Wu K, Watabe K. MicroRNAs in cancer stem cells: new regulators of stemness. Curr Pharm Design. 2014:20(33):5319-27.

46. Cheng S, Huang Y, Lou C, He Y, Zhang Y, Zhang Q. FSTL1 enhances chemoresistance and maintains stemness in breast cancer cells via integrin beta3/Wnt signaling under miR-137 regulation. Cancer Biol Ther. 2019;20(3):328-37.
47. Bonetti P Climent M, Panebianco F Tordonato C Santoro A Marzi MJ Pelicci PG, Ventura A, Nicassio F. Dual role for miR-34a in the control of early progenitor proliferation and commitment in the mammary gland and in breast cancer. Oncogene. 2019;38(3):360-74.

48. Sun X, Xu C, Tang SC, Wang J, Wang H, Wang P, Du N, Qin S, Li G, Xu $S$, et al. Let-7c blocks estrogen-activated Wnt signaling in induction of self-renewal of breast cancer stem cells. Cancer Gene Ther. 2016;23(4):83-9.

49. Sun X, Xu C, Xiao G, Meng J, Wang J, Tang SC, Qin S, Du N, Li G, Ren H, et al. Breast cancer stem-like cells are sensitized to tamoxifen induction of self-renewal inhibition with enforced Let-7c dependent on Wnt blocking. Int J Mol Med. 2018;41(4):1967-75.

50. Troschel FM, Böhly N, Borrmann K, Braun T, Schwickert A, Kiesel L, Eich HT, Götte M, Greve B. miR-142-3p attenuates breast cancer stem cell characteristics and decreases radioresistance in vitro. Tumour Biol. 2018:40(8):1010428318791887.

51. Wolfson B, Eades G, Zhou Q. Roles of microRNA-140 in stem cell-associated early stage breast cancer. World J Stem Cells. 2014;6(5):591-7.

52. Wu D, Zhang J, Lu Y, Bo S, Li L, Wang L, Zhang Q, Mao J. miR-140-5p inhibits the proliferation and enhances the efficacy of doxorubicin to breast cancer stem cells by targeting Wnt1. Cancer Gene Ther. 2019;26(3-4):74-82.

53. El Helou R, Pinna G, Cabaud O, Wicinski J, Bhajun R, Guyon L, Rioualen C, Finetti P, Gros A, Mari B, et al. miR-600 acts as a bimodal switch that regulates breast cancer stem cell fate through WNT signaling. Cell Rep. 2017;18(9):2256-68.

54. Lv C, Li F, Li X, Tian Y, Zhang Y, Sheng X, Song Y, Meng Q, Yuan S, Luan $L$, et al. MiR-31 promotes mammary stem cell expansion and breast tumorigenesis by suppressing Wnt signaling antagonists. Nat Commun. 2017;8(1):1036

55. Takebe N, Miele L, Harris PJ, Jeong W, Bando H, Kahn M, Yang SX, Ivy SP Targeting Notch, Hedgehog, and Wnt pathways in cancer stem cells: clinical update. Nat Rev Clin Oncol. 2015;12(8):445-64.

56. Braune EB, Seshire A, Lendahl U. Notch and Wnt dysregulation and its relevance for breast cancer and tumor initiation. Biomedicines. 2018:6(4):101.

57. Li L, Tang P, Li S, Qin X, Yang H, Wu C, Liu Y. Notch signaling pathway networks in cancer metastasis: a new target for cancer therapy. Med Oncol (Northwood Lond Engl). 2017;34(10):180.

58. Park EY, Chang E, Lee EJ, Lee HW, Kang HG, Chun KH, Woo YM, Kong HK, Ko JY, Suzuki H, et al. Targeting of miR34a-NOTCH1 axis reduced breast cancer stemness and chemoresistance. Cancer Res. 2014;74(24):7573-82

59. Kang L, Mao J, Tao Y, Song B, Ma W, Lu Y, Zhao L, Li J, Yang B, Li L. MicroRNA-34a suppresses the breast cancer stem cell-like characteristics by downregulating Notch1 pathway. Cancer Sci. 2015;106(6):700-8.

60. Yu F, Jiao Y, Zhu Y, Wang Y, Zhu J, Cui X, Liu Y, He Y, Park EY, Zhang H, et al. MicroRNA 34c gene down-regulation via DNA methylation promotes self-renewal and epithelial-mesenchymal transition in breast tumorinitiating cells. J Biol Chem. 2012;287(1):465-73.

61. Xiao G, Li X, Li G, Zhang B, Xu C, Qin S, Du N, Wang J, Tang SC, Zhang J, et al. MiR-129 blocks estrogen induction of NOTCH signaling activity in breast cancer stem-like cells. Oncotarget. 2017:8(61):103261-73.

62. Hu Y, Guo R, Wei J, Zhou Y, Ji W, Liu J, Zhi X, Zhang J. Effects of PI3K inhibitor NVP-BKM120 on overcoming drug resistance and eliminating cancer stem cells in human breast cancer cells. Cell Death Dis. 2015;6(12):e2020.

63. Guerrero-Zotano A, Mayer IA, Arteaga CL. PI3K/AKT/mTOR: role in breast cancer progression, drug resistance, and treatment. Cancer Metastasis Rev. 2016;35(4):515-24

64. Nitulescu GM, Van De Venter M, Nitulescu G, Ungurianu A, Juzenas P, Peng Q, Olaru OT, Grădinaru D, Tsatsakis A, Tsoukalas D, et al. The Akt pathway in oncology therapy and beyond (Review). Int J Oncol. 2018;53(6):2319-31

65. Sarbassov DD, Guertin DA, Ali SM, Sabatini DM. Phosphorylation and regulation of Akt/PKB by the rictor-mTOR complex. Science. 2005:307(5712):1098-101.

66. Hu M, Zhu S, Xiong S, Xue X, Zhou X. MicroRNAs and the PTEN/PI3K/Akt pathway in gastric cancer (Review). Oncol Rep. 2019;41(3):1439-54.

67. Li YJ, Li XF, Yang EH, Shi M. Reserch advances on the role of PI3KJAKT signaling pathway and MiRNA in acute T-cell lymphocytic leukemia - review. Zhongguo shi yan xue ye xue za zhi. 2019;27(4):1344-7. 
68. Yang Z, Han Y, Cheng K, Zhang G, Wang X. miR-99a directly targets the mTOR signalling pathway in breast cancer side population cells. Cell Proliferation. 2014;47(6):587-95.

69. Bahena-Ocampo I, Espinosa M, Ceballos-Cancino G, Lizarraga F, CamposArroyo D, Schwarz A, Maldonado V, Melendez-Zajgla J, Garcia-Lopez P. miR-10b expression in breast cancer stem cells supports self-renewal through negative PTEN regulation and sustained AKT activation. EMBO Rep. 2016;17(5):648-58.

70. Li B, Lu Y, Wang H, Han X, Mao J, Li J, Yu L, Wang B, Fan S, Yu X, et al. miR221/222 enhance the tumorigenicity of human breast cancer stem cells via modulation of PTEN/Akt pathway. Biomedicine pharmacotherapy = Biomedecine pharmacotherapie. 2016;79:93-101.

71. Han M, Liu M, Wang Y, Chen X, Xu J, Sun Y, Zhao L, Qu H, Fan Y, Wu C. Antagonism of miR-21 reverses epithelial-mesenchymal transition and cancer stem cell phenotype through AKT/ERK1/2 inactivation by targeting PTEN. PloS One. 2012;7(6):e39520.

72. Pietersen AM, Evers B, Prasad AA, Tanger E, Cornelissen-Steijger P, Jonkers $J$, van Lohuizen M. Bmi1 regulates stem cells and proliferation and differentiation of committed cells in mammary epithelium. Current biology: CB. 2008;18(14):1094-9.

73. Adorno M, Sikandar S, Mitra SS, Kuo A, Nicolis Di Robilant B, HaroAcosta V, Ouadah Y, Quarta M, Rodriguez J, Qian D, et al. Usp16 contributes to somatic stem-cell defects in Down's syndrome. Nature. 2013;501(7467):380-4.

74. Park IK, Morrison SJ, Clarke MF. Bmi1, stem cells, and senescence regulation. J Clin Investig. 2004;113(2):175-9.

75. Sharpless NE, DePinho RA. The INK4A/ARF locus and its two gene products. Curr Opin Genet Dev. 1999;9(1):22-30.

76. Lee YC, Chang WW, Chen YY, Tsai YH, Chou YH, Tseng HC, Chen HL, Wu CC, Chang-Chien J, Lee HT, et al. Hsp90a mediates BMI1 expression in breast cancer stem/progenitor cells through facilitating nuclear translocation of C-Myc and EZH2. Int J Mol Sci. 2017;18(9):1986.

77. Dimri M, Carroll JD, Cho JH, Dimri GP. microRNA-141 regulates BMI1 expression and induces senescence in human diploid fibroblasts. Cell cycle (Georgetown Tex). 2013;12(22):3537-46.

78. Dong P, Kaneuchi M, Watari H, Hamada J, Sudo S, Ju J, Sakuragi N. MicroRNA-194 inhibits epithelial to mesenchymal transition of endometrial cancer cells by targeting oncogene BMI-1. Mol Cancer. 2011;10:99.

79. He X, Dong Y, Wu CW, Zhao Z, Ng SS, Chan FK, Sung JJ, Yu J. MicroRNA-218 inhibits cell cycle progression and promotes apoptosis in colon cancer by downregulating BMI1 polycomb ring finger oncogene. Molecular medicine (Cambridge Mass). 2013;18(1):1491-8.

80. Shimono Y, Mukohyama J, Nakamura S, Minami H. MicroRNA regulation of human breast cancer stem cells. J Clin Med. 2015;5(1):2.

81. Shimono Y, Zabala M, Cho RW, Lobo N, Dalerba P, Qian D, Diehn M, Liu H, Panula SP, Chiao E, et al. Downregulation of miRNA-200c links breast cancer stem cells with normal stem cells. Cell. 2009;138(3):592-603.

82. Zhu Y, Yu F, Jiao Y, Feng J, Tang W, Yao H, Gong C, Chen J, Su F, Zhang $Y$, et al. Reduced miR-128 in breast tumor-initiating cells induces chemotherapeutic resistance via Bmi-1 and ABCC5. Clin Cancer Res. 2011;17(22):7105-15.
83. Lee YS, Choi KM, Kim W, Jeon YS, Lee YM, Hong JT, Yun YP, Yoo HS. Hinokitiol inhibits cell growth through induction of S-phase arrest and apoptosis in human colon cancer cells and suppresses tumor growth in a mouse xenograft experiment. J Natural Products. 2013;76(12):2195-202.

84. Liu S, Yamauchi H. p27-Associated G1 arrest induced by hinokitiol in human malignant melanoma cells is mediated via down-regulation of pRb, Skp2 ubiquitin ligase, and impairment of Cdk2 function. Cancer Lett. 2009;286(2):240-9.

85. Chen SM, Wang BY, Lee CH, Lee HT, Li JJ, Hong GC, Hung YC, Chien PJ, Chang CY, Hsu LS, et al. Hinokitiol up-regulates miR-494-3p to suppress BMI1 expression and inhibits self-renewal of breast cancer stem/progenitor cells. Oncotarget. 2017;8(44):76057-68.

86. Galoczova M, Coates P, Vojtesek B. STAT3, stem cells, cancer stem cells and p63. Cell Mol Biol Lett. 2018;23:12.

87. You L, Wang Z, Li H, Shou J, Jing Z, Xie J, Sui X, Pan H, Han W. The role of STAT3 in autophagy. Autophagy. 2015;11(5):729-39.

88. Levy DE, Darnell JE Jr. Stats: transcriptional control and biological impact. Nat Rev Mol Cell Biol. 2002;3(9):651-62.

89. Darnell JE Jr, Kerr IM, Stark GR. Jak-STAT pathways and transcriptional activation in response to IFNs and other extracellular signaling proteins. Science. 1994;264(5164):1415-21.

90. Fagard R, Metelev V, Souissi I, Baran-Marszak F. STAT3 inhibitors for cancer therapy: Have all roads been explored? Jak-stat. 2013;2(1):e22882.

91. Zhong Z, Wen Z, Darnell JE. Jr.: Stat3: a STAT family member activated by tyrosine phosphorylation in response to epidermal growth factor and interleukin-6. Science. 1994;264(5155):95-8.

92. Yu H, Lee H, Herrmann A, Buettner R, Jove R. Revisiting STAT3 signalling in cancer: new and unexpected biological functions. Nat Rev Cancer. 2014;14(11):736-46.

93. Zhang H, Cai K, Wang J, Wang X, Cheng K, Shi F, Jiang L, Zhang Y, Dou J. MiR-7, inhibited indirectly by lincRNA HOTAIR, directly inhibits SETDB1 and reverses the EMT of breast cancer stem cells by downregulating the STAT3 pathway. Stem cells (Dayton, Ohio). 2014;32(11):2858-68.

94. Qin AY, Zhang XW, Liu L, Yu JP, Li H, Wang SZ, Ren XB, Cao S. MiR-205 in cancer: an angel or a devil? Eur J Cell Biol. 2013;92(2):54-60.

95. Wu H, Zhu S, Mo YY. Suppression of cell growth and invasion by miR-205 in breast cancer. Cell Res. 2009;19(4):439-48.

96. Greene SB, Gunaratne PH, Hammond SM, Rosen JM. A putative role for microRNA-205 in mammary epithelial cell progenitors. J Cell Sci. 2010;123(Pt 4):606-18.

97. Mayoral-Varo V, Calcabrini A, Sánchez-Bailón MP, Martín-Pérez J. miR205 inhibits stem cell renewal in SUM159PT breast cancer cells. PloS one. 2017;12(11):e0188637.

98. Zhang Y, Wang Z, Gemeinhart RA. Progress in microRNA delivery. J Controlled Release. 2013;172(3):962-74.

\section{Publisher's Note}

Springer Nature remains neutral with regard to jurisdictional claims in published maps and institutional affiliations.
Ready to submit your research? Choose BMC and benefit from:

- fast, convenient online submission

- thorough peer review by experienced researchers in your field

- rapid publication on acceptance

- support for research data, including large and complex data types

- gold Open Access which fosters wider collaboration and increased citations

- maximum visibility for your research: over $100 \mathrm{M}$ website views per year

At BMC, research is always in progress.

Learn more biomedcentral.com/submissions 